\title{
Effects of Impurities on Alumina-Niobium Interfacial Microstructures
}

\author{
Joseph T. McKeown, Joshua D. Sugar, \\ Ronald Gronsky, and Andreas M. Glaeser* \\ Department of Materials Science and Engineering, \\ University of California \\ $\&$ \\ Ceramic Science Program \\ Materials Sciences Division \\ Lawrence Berkeley National Laboratory, \\ Berkeley, CA 94720
}

\begin{abstract}
Optical microscopy, scanning electron microscopy, and transmission electron microscopy were employed to examine the interfacial microstructural effects of impurities in alumina substrates used to fabricate alumina-niobium interfaces via liquid-film-assisted joining. Three types of alumina were used: undoped high-purity single-crystal sapphire; a high-purity, high-strength polycrystalline alumina; and a lower-purity, lower-strength polycrystalline alumina. Interfaces formed between niobium and both the sapphire and high-purity polycrystalline alumina were free of detectable levels of impurities. In the lower-purity alumina, niobium silicides were observed at the aluminaniobium interface and on alumina grain boundaries near the interface. These silicides formed in small-grained regions of the alumina and were found to grow from the interface into the alumina along grain boundaries. Smaller silicide precipitates found on grain boundaries are believed to form upon cooling from the bonding temperature.
\end{abstract}

Keywords: alumina, niobium, ceramic-metal interfaces, purity, silicides

* Corresponding author. Tel.: 01-510-486-7262; fax: 01-510-486-6904.

E-mail address: aglaeser@sapphire.berkeley.edu. 


\section{INTRODUCTION}

During the fabrication of ceramic-metal interfaces, impurities present in both the ceramic and metal can segregate to the interface and affect the fracture strength of the final assembly directly through their effect on interfacial adhesion and fracture path, and indirectly through their effect on plastic dissipation accompanying fracture [1-6]. Whether the effects of impurities are beneficial or detrimental depends on multiple factors, including the chemical species present and the formation of secondary phases.

The interfacial fracture energy, $\bar{G}_{C}$, of a ceramic-metal interface $[1,7,8]$ is a function of the work of adhesion, $W_{a d}$, and the dissipated work of plastic deformation in the metal, $W_{p}$ :

$$
\overline{\mathrm{G}}_{\mathrm{C}}=W_{a d}+W_{p}
$$

The plastic work has been shown to be a nonlinear function of the work of adhesion [7]:

$$
W_{p}=\left(W_{a d}\right)^{n}
$$

where $n$ is an empirical parameter that is greater than unity and depends on the materials system.

Fracture in alumina-niobium assemblies generally occurs at the interface in diffusionbonded samples processed with a dense, high-purity alumina. More generally, the fracture path and fracture energy are dependent on parameters such as alumina porosity, alumina purity, and impurity content of the niobium, which determine the interfacial microstructure and chemistry [16]. It is therefore of fundamental interest to understand the effects of impurities on the interfacial microstructure of an alumina-niobium interface.

Silicate phases can influence both the bonding process, and the fracture strength of bonded ceramic-metal interfaces. In studies of alumina-platinum interfaces [3], intervening amorphous and crystalline silicate phases were obtained by deposition of a silica layer onto the sapphire or alumina prior to bonding. Results showed that the amorphous phase played a dual role, accelerating the rate of diffusion bonding, leading to an interface with a small area fraction of defects and voids, but also 
degrading the interfacial fracture energy. The fracture energy was not adversely affected by the presence of crystalline silicates.

Alumina-niobium is a widely studied ceramic-metal system with bonded interfaces that are virtually free of thermal stresses due to closely matched thermal expansion coefficients. Niobium and alumina are also chemically compatible, producing interfaces with no chemical reaction layer when bonded in vacuum $[2,9,10]$. Considerable prior research has been conducted on the mechanical properties and interfacial characterization of the alumina-niobium system [2, 9-17]. In the case of alumina-niobium interfaces, niobium silicide formation has been observed in previous studies $[1,4,18]$. In the present study, polycrystalline alumina substrates of two distinct purities and single-crystal alumina (sapphire) substrates were used to fabricate alumina-niobium interfaces by liquid-film-assisted joining (LFAJ). The presence of brittle phases at the interface due to interaction with intergranular glassy phases in the alumina was investigated using optical microscopy, scanning electron microscopy, and transmission electron microscopy.

\section{Experimental Procedures}

Interfaces were fabricated with three types of aluminum oxide: undoped, high-purity, single-crystal sapphire (typically $\approx 99.996 \%$ pure, InsAco INC., Quakertown, PA); a high-purity, high-strength, fine-grain-size polycrystalline alumina ( $\approx 99.9 \%$ pure, SSA-999W, Nikкato Corp., Osaka, JAPAN); and a lower-purity, lower-strength, coarser-grain-size polycrystalline alumina ( $\approx 99.5 \%$ pure, AD995, Coors Technical Ceramic Co., Oak Ridge, TN). All assemblies were joined using a multilayer copper/niobium/copper interlayer with two $\approx 3.0-\mu \mathrm{m}$-thick copper layers flanking a $125-\mu$ m-thick $99.99 \%$ pure niobium foil (Goodfellow Corp., Malvern, PA). Assemblies were processed at $1400^{\circ} \mathrm{C}$ for $6 \mathrm{~h}$ with an applied load of $\approx 2 \mathrm{MPa}$ in a graphite-element hot press. Samples were heated to the bonding temperature at $4^{\circ} \mathrm{C} / \mathrm{min}$ and then cooled to room temperature at $2^{\circ} \mathrm{C} / \mathrm{min}$. During the bonding cycle, the copper melted to form a copper-rich liquid film that facilitated contact growth and bonding between the alumina and niobium. Details of the interface processing are available in prior publications $[9,17,19,20]$. 
Assemblies were machined into beams approximately $4 \mathrm{~cm}$ long with a $3 \mathrm{~mm} \times 3 \mathrm{~mm}$ cross-section. The interlayer was at the center of the length of the beams. The room-temperature fracture strength was determined using four-point bending.

Images of interfaces were taken in an optical microscope. Beams chosen for imaging were ultrasonically cleaned in isopropyl alcohol for approximately $15 \mathrm{~min}$. Cross-sections of interfaces were prepared with a diamond saw and then ground flat on 30- $\mu \mathrm{m}$ diamond paper and polished with progressively finer diamond grit, ending with a $0.05-\mu \mathrm{m}$ colloidal-silica suspension. Crosssections were then cleaned in acetone and isopropyl alcohol for approximately 15 min each.

SEM samples were prepared in the same manner as cross-sections used for optical microscopy. Electron microscopy was performed in a Hitachi S-4300 SE/N FE SEM.

TEM specimens were prepared from beams that failed within the ceramic and along the interface. Cross-sectional samples of the interface were machined into 3-mm discs and thinned mechanically by grinding, polishing, and dimpling until the center of the disc was $<20 \mu \mathrm{m}$ thick. The dimple was polished to a $0.05-\mu \mathrm{m}$ finish. Finally, a perforation was made in the center of the disc at the alumina-niobium interface by low-energy $\mathrm{Ar}^{+}$ions in an ion mill. Electron microscopy and energy dispersive spectrometry were performed in a JEOL 200CX and a Philips CM 200, both operating at an accelerating voltage of $200 \mathrm{kV}$.

\section{Results and Discussion}

Mechanical Properties of Assemblies

An assembly processed with sapphire substrates used undoped sapphire with the c-plane (0001) as the joining surface. All beams from this assembly failed along the sapphire-niobium interface at tensile stresses $\leq 177 \mathrm{MPa}$ [19]. Breakup of the initially continuous copper film during bonding was incomplete, leaving large patches of relatively weak copper-alumina interface along the bond plane that may account for the low strengths and the propensity for interfacial failure.

In joints prepared with polycrystalline alumina, disruption of the initially continuous copper film is more extensive, and the area fraction of alumina-niobium contact is higher. Joint 
properties were sensitive to the alumina characteristics. Joints processed using $99.9 \%$-pure alumina had a higher average fracture strength $(359 \mathrm{MPa})$ than those prepared with $99.5 \%$-pure alumina $(241 \mathrm{MPa})$ [19]. All of the $99.9 \%$-pure alumina joints and $\approx 75 \%$ of $99.5 \%$-pure alumina joints failed entirely in the alumina, and thus the relative fracture strengths reflect the differences in the alumina fracture properties. Grain size is the major factor responsible for this higher fracture strength. The average grain size is larger than or on the order of the size of flaws created during processing, so the defect that determines the strength scales with the average grain size. The average strength of beams prepared from the unbonded as-received $99.9 \%$-pure alumina was $\approx 560$ $\mathrm{MPa}$ [19]. Comparing grain sizes in as-received and bonded 99.9\%-pure alumina, the mean linear intercepts were $\approx 0.9$ and $\approx 1.2 \mu \mathrm{m}$, respectively [19]. The $99.5 \%$-pure alumina exhibited a bimodal grain size distribution, with the larger mode being $\approx 25 \mu \mathrm{m}$. A roughly linear relationship between strength and the inverse square root of grain size was previously reported in studies examining the grain size dependence of the fracture strength of a similar high-purity alumina [21]. A smaller grain size increases the number of initial contacts at the alumina-niobium interface during the bonding cycle, thus leading to increased void elimination at the interface.

The shift to ceramic failures in bonds prepared with polycrystalline aluminas indicates that the strength of the alumina-interlayer interface generally exceeded that of the adjoining alumina. Since all bonds involving $99.9 \%$-pure alumina failed in the ceramic, fracture surfaces alone provide no insight on the alumina-interlayer interfacial microstructure and chemistry. In joints processed with 99.5\%-pure alumina, examination of interfacial fracture surfaces was possible and revealed the presence of adherent islands of a silicide phase and tearing of niobium in bonded regions where the niobium was in contact with the finer-grain-size alumina regions $[18,20,24]$. This indicated that the small amount of glassy silicate phase present in the material may play a role in alumina-niobium contact formation and does modify the alumina-niobium interfacial microstructure. 


\section{Interface Characterization}

\section{Single-Crystal Sapphire Substrates}

FIGURE I is an optical micrograph of a sapphire-niobium interface in cross-section. The interface appears distinct and smooth. There are also no reaction phases present at the interface, as expected $[1,16,19,22]$. Sapphire eliminates the possibility of a glassy phase flowing to and filling interfacial voids [19]. Copper particles persist at the interface after bonding due to the low solubility of copper in niobium and a low rate of copper-niobium interdiffusion. These ductile particles affect the fracture strength of the joined assembly in a manner that depends specifically on the morphology and volume fraction of the copper $[18,20,23,24]$. The inset in Figure I shows two of these copper particles at increased magnification. There are two distinct copper particle morphologies, labeled "a" and "b." The particle labeled "a" is copper trapped in a niobium grainboundary groove. The grain boundary is not evident in the micrograph, but SEM images and chemical etching clearly show the boundary. The particle labeled " $b$ " forms as a result of copper film dewetting. FIgURE 2 is an SEM image of a sapphire-niobium interface in cross-section. The interface is free of secondary phases. Deviations from planarity are a result of local roughness on the surface of the sapphire. Energy-dispersive spectrometry (EDS) in both the SEM and TEM confirms that the interface is free of detectable levels of impurities.

High-Purity (99.9\%-Pure) Polycrystalline Alumina Substrates

FIgURE 3 is an optical micrograph of the alumina-niobium interface. Figure 4 is an SEM image of the same interface at higher magnification. The interface is free of secondary phases, consistent with expectations of a high-purity alumina, and appears rough on the scale of the alumina grain size due to the grooving of the alumina grains during bonding. The niobium has conformed to the alumina surface, penetrating into the alumina grain-boundary grooves. Again, EDS in both the SEM and TEM detected no impurities.

Lower-Purity (99.5\%-Pure) Polycrystalline Alumina Substrates

FIGURE 5 shows a cross-sectional optical micrograph of an alumina-niobium interface processed using 99.5\%-pure alumina. Small silicide precipitates are evident at and slightly away 
from the interface. The interface again appears rough due to grain-boundary grooving, and fractography shows that the silicide precipitates are present in small-grained regions of the alumina. This is due to a higher grain-boundary density in these regions, leading to a higher silicon flux per unit area of alumina and a higher local concentration of silicon at the interface during bonding as a result of the glassy phase flowing to wet the interface. The boxed regions labeled "a" and " $b$ " correspond to the SEM images of silicide precipitates at and near the alumina-niobium interface in, respectively, Figures 6 and 7. The precipitates that are situated away from the interface lie along alumina grain boundaries.

In Figure 6, the precipitates labeled (1) lie $\approx 1.5 \mu \mathrm{m}$ away from the larger precipitates. The precipitate labeled (2) is $\approx 1 \mu \mathrm{m}$ away from the alumina-niobium interface. FIgURE 8 is a bright-field TEM image of a silicide precipitate at the alumina-niobium interface. In FIGURE 6, 7, and 8, the silicide precipitates extend $\approx 4 \mu \mathrm{m}$ along alumina grain boundaries. FIGURE 9 shows what appears to be a small isolated precipitate situated $\approx 0.2 \mu \mathrm{m}$ away from the interface. It should be noted that these distances are in the plane of observation. If a precipitate is inclined relative to the interface, the observed and actual morphology and microstructure may be slightly different due to sectioning during sample preparation.

EDS in the SEM indicates that the precipitates contain both niobium and silicon. A sample spectrum from the precipitate in Figure 7 is shown in Figure io. EDS with a 10-nm probe size was conducted in the TEM. FIGURE II shows EDS spectra obtained from two locations within the silicide in FIgURE 8, from a grain at the alumina-niobium interface and from an adjacent grain farther from the interface. The scales in Figures io and II reflect the intensity of each peak relative to the intensity of the $\mathrm{Nb} \mathrm{L}$ peak. The iron and chromium peaks in the spectra are a result of ion milling residuals. The copper peak is due to incorporated copper, present as a result of the liquidfilm-assisted joining technique. The silicide composition was found to vary with microstructural location (i.e., proximity to the alumina-niobium interface). The energy scales for the two spectra in the figure are offset by $2 \mathrm{keV}$ to facilitate a side-by-side comparison of the niobium and silicon peak heights, and to show the change in the $\mathrm{Nb}$ :Si peak height ratio. In the binary niobium-silicon phase 
diagram [25], $\mathrm{Nb}_{5} \mathrm{Si}_{3}$ coexists with niobium at $1400^{\circ} \mathrm{C}$, and is stable over a narrow range of composition. The ternary niobium-silicon-copper system has only been studied at $800^{\circ} \mathrm{C}$ and $875^{\circ} \mathrm{C}$ [26]; there is little copper incorporation in the silicides, and little adjustment in the stoichiometry ranges for silicide stability. In the present study, EDS indicates the $\mathrm{Nb}$ :Si ratio of the silicide at the interface is $\approx 4.5: 3$, and that the phase incorporates $\approx 5.5$ atomic $\%$ copper. The $\mathrm{Nb}: \mathrm{Si}$ ratio agrees with the EDS results of Kruzic et al. [18] from adherent islands of silicide precipitates on alumina fracture surfaces. The composition vis-a-vis the binary phase diagram and available isothermal ternary sections would suggest a mixture of $\approx 95 \% \mathrm{Nb}_{5} \mathrm{Si}_{3}$ and $\approx 5 \% \mathrm{NbSi}_{2}$, however, the grain is single phase and electron diffraction analysis [27] indicates the structure is consistent with " $\mathrm{Nb}_{5} \mathrm{Si}_{3}$ ". In the adjacent grain, the spectrum was obtained from a region $\approx 1.5 \mu \mathrm{m}$ from the interface. The $\mathrm{Nb}: \mathrm{Si}$ ratio is 3.8:3, and the overall composition would again lie in the $\mathrm{Nb}_{5} \mathrm{Si}_{3}$ and $\mathrm{NbSi}_{2}$ two-phase field [25], and contain $\approx 80 \% \mathrm{Nb}_{5} \mathrm{Si}_{3}$ and $\approx 20 \% \mathrm{NbSi}_{2}$. However, the grain itself is again single phase. It seems unlikely that the signal was acquired from more than one grain through the thickness of the sample, or that there is a contribution from an adjoining grain. Instead, " $\mathrm{Nb}_{5} \mathrm{Si}_{3}$ " may exist over a wider compositional range at $1400^{\circ} \mathrm{C}$, and compositional variations with depth may be associated with diffusional growth of the phase. Further analysis of the phase (EDS, diffraction), microstructure (defect structure, orientation relationship), and mechanism of formation of these niobium silicide precipitates will be the subject of future research and publication.

The presence of niobium silicide precipitates both at and slightly away from the interface indicates two possibly distinct mechanisms for their formation. A glassy silicate phase is present at grain boundaries in the bulk alumina. At elevated temperatures, $\mathrm{SiO}_{2}$ flows to the interface. In the case of precipitates at the interface, nucleation most likely occurs at the interface of the niobium metal in contact with alumina grain boundaries, and silicon that has diffused to the interface. The precipitate then grows into the alumina, down the grain boundary where the silicon concentration is higher. The presence of grain boundaries (see FIGURE 8) within the niobium silicide precipitates suggests more than one nucleation site along the grain boundary. These precipitates then grow and 
impinge upon each other. The development of isolated precipitates on alumina grain boundaries at some depth below the alumina-niobium interface would seemingly require niobium diffusion down the alumina grain boundaries and locally favorable nucleation conditions. The small size of these particles suggests that nucleation and growth occurs during cooling. At temperature, the concentration of niobium should decrease with depth below the interface, and there should be an opposing gradient in the silica content. As the material is cooled, dissolved niobium will flow back to the niobium interlayer, resulting in a local niobium concentration maximum at some depth below the surface. As the temperature decreases, conditions suitable for silicide nucleation may develop at points where the supersaturation is highest.

Niobium silicides affect the interfacial adhesion, and therefore the interfacial fracture energy. Fractography and EDS data obtained from fracture surfaces $[18,20]$ indicate that the fracture path proceeded either along the $\mathrm{Nb}-\mathrm{Nb}_{5} \mathrm{Si}_{3}$ interface or through the $\mathrm{Nb}_{5} \mathrm{Si}_{3}$ particle. The interfacial fracture energies of $\mathrm{Nb}-\mathrm{Nb}_{5} \mathrm{Si}_{3}$ interfaces and $\mathrm{Al}_{2} \mathrm{O}_{3}-\mathrm{Nb}_{5} \mathrm{Si}_{3}$ interfaces have been reported as, respectively, $\geq 33.7 \mathrm{~J} / \mathrm{m}^{2}$ and $\approx 16 \mathrm{~J} / \mathrm{m}^{2}[28] . \mathrm{Nb}_{5} \mathrm{Si}_{3}$ is a brittle phase, with $K_{\mathrm{IC}} \approx 3 \mathrm{MPa} \cdot \mathrm{m}^{1 / 2}[29]$. It is possible that the crack initially propagated along the $\mathrm{Al}_{2} \mathrm{O}_{3}-\mathrm{Nb}_{5} \mathrm{Si}_{3}$ interface and then deviated either along the $\mathrm{Nb}-\mathrm{Nb}_{5} \mathrm{Si}_{3}$ interface or through the silicide particle.

\section{Conclusions}

Examination of alumina-niobium interfaces processed via liquid-film-assisted joining using optical microscopy, SEM, and TEM revealed that niobium silicides form in samples fabricated with a low-purity polycrystalline alumina. Interfaces processed with single-crystal sapphire and high-purity polycrystalline alumina were free of detectable levels of impurities.

Silicide precipitates form at the alumina-niobium interface and along alumina grain boundaries near the interface. Silicides at the interface grow into the alumina grain boundaries. Smaller silicide precipitates along grain boundaries are believed to form upon cooling from the bonding temperature. The composition of silicide precipitates was found to depend on proximity 
to the alumina-niobium interface. Precipitates at the interface and in physical contact with niobium were identified as $\mathrm{Nb}_{5} \mathrm{Si}_{3}$. At locations situated away from the interface, the niobium concentration was reduced. This suggests that copper incorporation widens the compositional stability range for " $\mathrm{Nb}_{5} \mathrm{Si}_{3}$ " at elevated temperatures. 


\section{Acknowledgments}

This research was supported by the Director, Office of Science, Office of Basic Energy Sciences, Division of Materials Science and Engineering, of the U.S. Department of Energy under Contract No. DE-AC03-76SF00098.

The authors acknowledge the support of the staff, especially Dr. Tamara Radetic, and facilities at the National Center for Electron Microscopy, along with the assistance of Dr. Seth Taylor. 


\section{REFERENCES}

1. Elssner G, Korn D, and Rühle M. The influence of interface impurities on fracture energy of UHV diffusion bonded metal-ceramic bicrystals. Scr. Metall. Mater. 1994; 31 (8): 1037-42.

2. Florjancic $M$, Mader W, Rühle $M$, and Turwitt $M$. HREM and diffraction studies of an $\mathrm{Al}_{2} \mathrm{O}_{3} / \mathrm{Nb}$ interface. J. Phys. (Paris) 1985; 46 (C4): 129-33.

3. De Graef M, Dalgleish BJ, Turner MR, and Evans AG. Interfaces between alumina and platinum: structure, bonding and fracture resistance. Acta Metall. Mater. 1992; 40 (Suppl. issue): $\mathrm{S} 333-44$.

4. Korn D, Elssner G, Fischmeister HF, and Rühle M. Influence of interface impurities on the fracture energy of UHV bonded niobium-sapphire bicrystals. Acta Metall. Mater. 1992; 40 (Suppl. issue): S355-60.

5. Korn D, Elssner G, Cannon RM, and Ruhle M. Fracture properties of interfacially doped Nb$\mathrm{Al}_{2} \mathrm{O}_{3}$ bicrystals: I, fracture characteristics. Acta Materialia 2002; 50 (15): 3881-3901.

6. Cannon RM, Korn D, Elssner G, and Ruhle M. Fracture properties of interfacially doped Nb$\mathrm{Al}_{2} \mathrm{O}_{3}$ bicrystals: II, relation of interfacial bonding, chemistry and local plasticity. Acta Materialia 2002; 50 (15): 3903-3925.

7. Jokl ML, Vitek V, and McMahon CJ, Jr. A microscopic theory of brittle fracture in deformable solids: a relation between ideal work to fracture and plastic work. Acta Metall. 1980; 28 (11): 1479-88.

8. Cannon RM, Jayaram V, Dalgleish BJ, and Fisher RM. Microstructural and chemical components of ceramic-metal interfacial fracture energies. Electronic Packaging Materials Science II Symposium. Mater Res Soc. Palo Alto, CA, April 15-18; 1986.

9. Shalz ML, Dalgleish BJ, Tomsia AP, Cannon RM, and Glaeser AM. Ceramic joining III bonding of alumina via Cu/Nb/Cu interlayers. J. Mater. Sci. 1994; 29 (14): 3678-90.

10. Knauss $\mathrm{D}$ and Mader W. Chemical composition and lattice relaxations at diffusion-bonded $\mathrm{Nb} / \mathrm{Al}_{2} \mathrm{O}_{3}$ interfaces. Ultramicroscopy 1991; 37 (1-4): 247-262.

11. Nicholas MG, Forgan RRG, and Poole DM. The adhesion of metal/alumina interfaces. J. Mater. Sci. 1968; 3: 9-14.

12. Burger K, Mader W, and Rühle M. Structure, chemistry and diffusion bonding of metal/ceramic interfaces. Ultramicroscopy 1987; 22 (1-4): 1-13.

13. Mader $\mathrm{W}$ and Rühle $\mathrm{M}$. Electron microscopy studies of defects at diffusion-bonded $\mathrm{Nb} / \mathrm{Al}_{2} \mathrm{O}_{3}$ interfaces. Acta Metall. 1989; 37 (3): 853-66.

14. Mayer J, Dura J, Flynn CP, and Rühle M. Electron microscopy studies of $\mathrm{Nb}-\mathrm{Al}_{2} \mathrm{O}_{3}$ interfaces formed by molecular beam epitaxy. Surface and Coatings Technol. 1990; $43 / 44$ (1): 199-212.

15. O'Dowd NP, Stout MG, and Shih CF. Fracture toughness of alumina-niobium interfaces: experiments and analyses. Philos. Mag. A (Phys. Cond. Matter, Defects and Mech. Prop.) 1992; 66 (6): 1037-64.

16. Rühle M. Structure and composition of metal/ceramic interfaces. J. Eur. Ceram. Soc. 1995; 16 (3): 353-65.

17. Marks RA, Chapman DR, Danielson DT, and Glaeser AM. Joining of alumina via copper/niobium/copper interlayers. Acta Mater. 2000; 48 (18-19): 4425-38.

18. Kruzic JJ, Marks RA, Yoshiya M, Glaeser AM, Cannon RM, and Ritchie RO. Fracture and fatigue behavior at ambient and elevated temperatures of alumina bonded with copper/niobium/copper interlayers. J. Am. Ceram. Soc. 2002; 85 (10): 2531-41. 
19. Marks RA, Sugar JD, and Glaeser AM. Ceramic joining IV. effects of processing conditions on the properties of alumina joined via $\mathrm{Cu} / \mathrm{Nb} / \mathrm{Cu}$ interlayers. J. Mater. Sci. 2001; 36 (23): 5609-24.

20. Sugar JD, McKeown JT, Marks RA, and Glaeser AM. Liquid-film assisted formation of alumina-niobium interfaces. J. Am. Ceram. Soc. 2002; 85 (10): 2523-30.

21. Seidel J, Claussen N, and Rödel J. Reliability of alumina ceramics: effect of grain size. J. Eur. Ceram. Soc. 1995; 15 (5): 395-404.

22. Rühle M and Evans AG. Structure and chemistry of metal/ceramic interfaces. Mater. Sci. Engin. 1989; A107: 187-87.

23. Dauskardt RH, Lane M, Ma Q, and Krishna N. Adhesion and debonding of multi-layer thin film structures. Eng. Fract. Mech. 1998; 61 (1): 141-62.

24. McKeown JT, Sugar JD, Gronsky R, and Glaeser AM. Processing of alumina-niobium interfaces via liquid-film-assisted joining. Weld. J. 2005; 84 (3).

25. Massalski TB and Okamoto H, editors. Binary Alloy Phase Diagrams, 2nd ed. Materials Park, $\mathrm{OH}:$ ASM International; 1990.

26. Zankl R and Malter R. Phase-Equilibria In The System Copper-Niobium-Silicon. Z. Metallk. 1981; 72 (10): 720-724.

27. McKeown JT, Processing and Characterization of Alumina/Niobium Interfaces Produced via Liquid Film Assisted Joining, Department of Materials Science and Engineering, University of California, Berkeley, (2003).

28. Shaw L, Miracle D, and Abbaschian R. Microstructure and mechanical properties of metal/oxide and metal/silicide interfaces. Acta Metall. Mater. 1995; 43 (12): 4267-79.

29. Nekkanti RK and Dimiduk DM. Ductile-phase toughening in niobium-niobium silicide powder processed composites. In: Anton DL, Martin PL, Miracle DB, and McMeeking R, editors. Materials Research Society Symposium Proceedings, vol. 194, Intermetallic Matrix Composites. Pittsburgh, PA: Materials Research Society; 1990, p. 175-82. 


\section{Figure Captions}

Figure I: Optical micrograph of a sapphire-niobium interface in cross-section. Copper particles persist at the interface after the bonding cycle, shown at a larger scale in the inset.

FiguRE 2: SEM image of a sapphire-niobium interface in cross-section.

Figure 3: Optical micrograph of a high-purity alumina-niobium interface in cross-section. The interface is free of secondary phases.

FIgUre 4: SEM image of a high-purity alumina-niobium interface in cross-section. Note the rough interface, due to penetration of the niobium into the alumina grain-boundary grooves and other surface irregularities.

Figure 5: Optical micrograph of a lower-purity alumina-niobium interface in cross-section. Silicide precipitates are evident at the interface. The boxes labeled "a" and "b" are the regions shown in the SEM images of FIgUREs 6 and 7, respectively.

Figure 6: SEM image of niobium silicide precipitates at the alumina-niobium interface and slightly away from the interface at alumina grain boundaries.

FIGURE 7: SEM image of a niobium silicide precipitate at the alumina-niobium interface and extending away from the interface along an alumina grain boundary.

Figure 8: Bright-field TEM image of a niobium silicide precipitate extending from the aluminaniobium interface into the alumina along a grain boundary.

FIgURE 9: Bright-field TEM image of a niobium silicide precipitate away from the aluminaniobium interface at an alumina grain boundary.

FIGURE IO: EDS spectrum obtained in the SEM from the region indicated. The precipitate is a niobium silicide.

FIgURE II: EDS spectra obtained in the TEM from the regions indicated. The composition of the precipitate in the grain at the alumina-niobium interface (top spectrum) is consistent with the $\mathrm{Nb}_{5} \mathrm{Si}_{3}$ phase. The $\mathrm{Nb}: \mathrm{Si}$ ratio is lower away from the interface (bottom spectrum). 


\section{Figures}

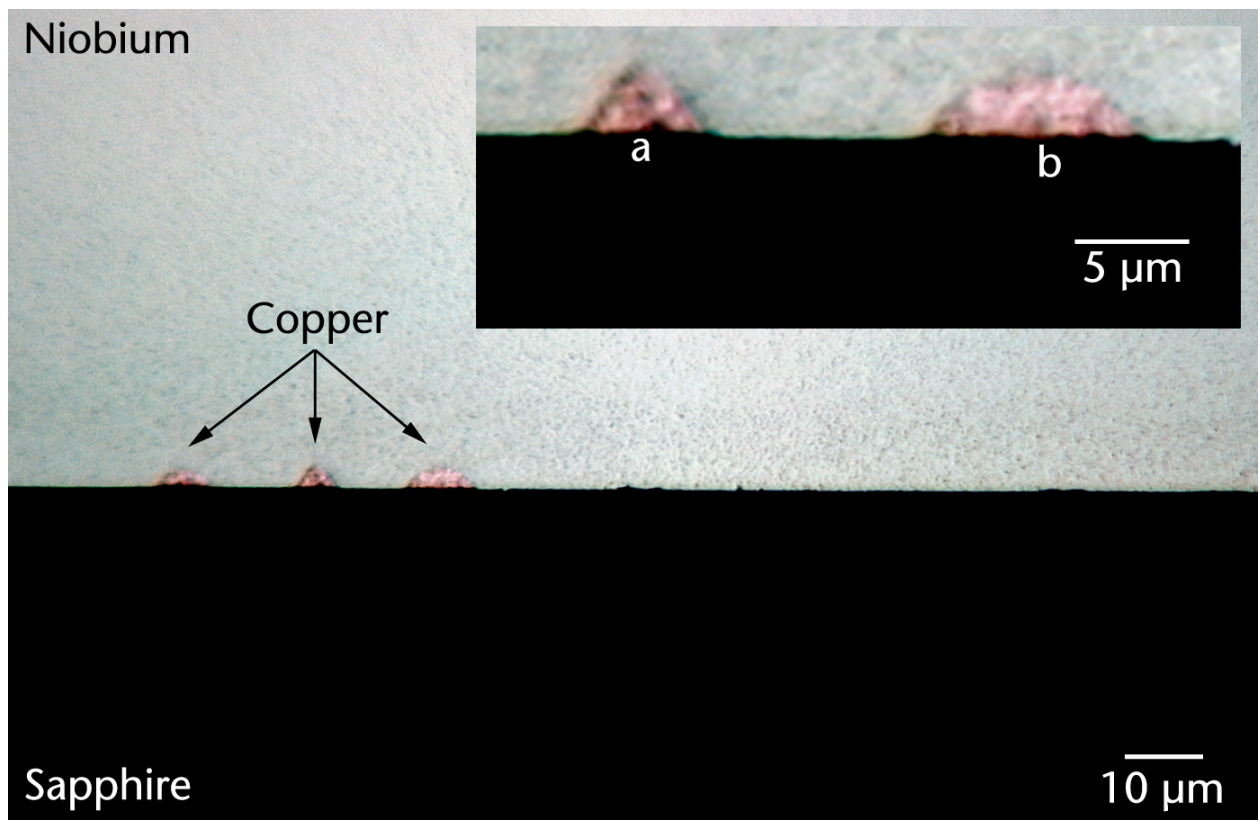

Figure I: Optical micrograph of a sapphire-niobium interface in cross-section. Copper particles persist at the interface after the bonding cycle, shown at a larger scale in the inset. 


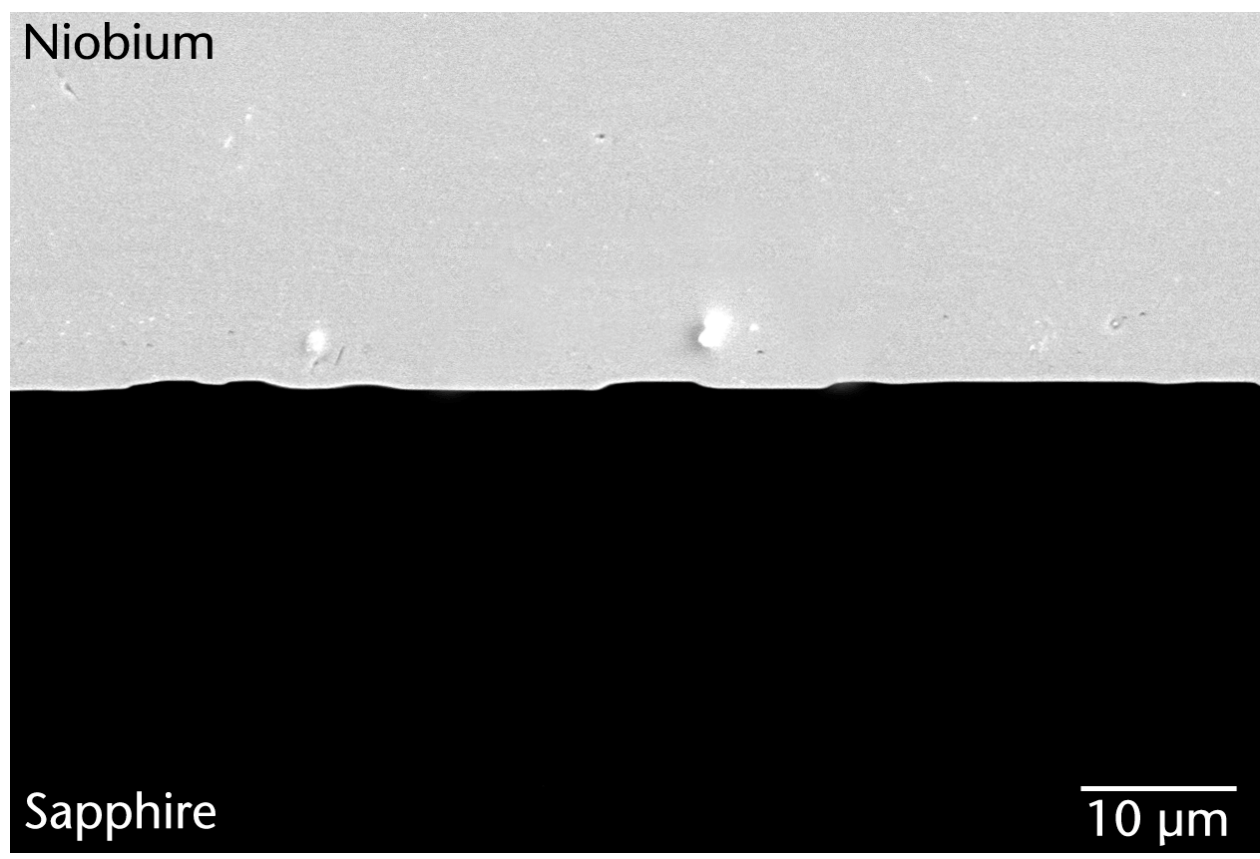

Figure 2: SEM image of a sapphire-niobium interface in cross-section. 


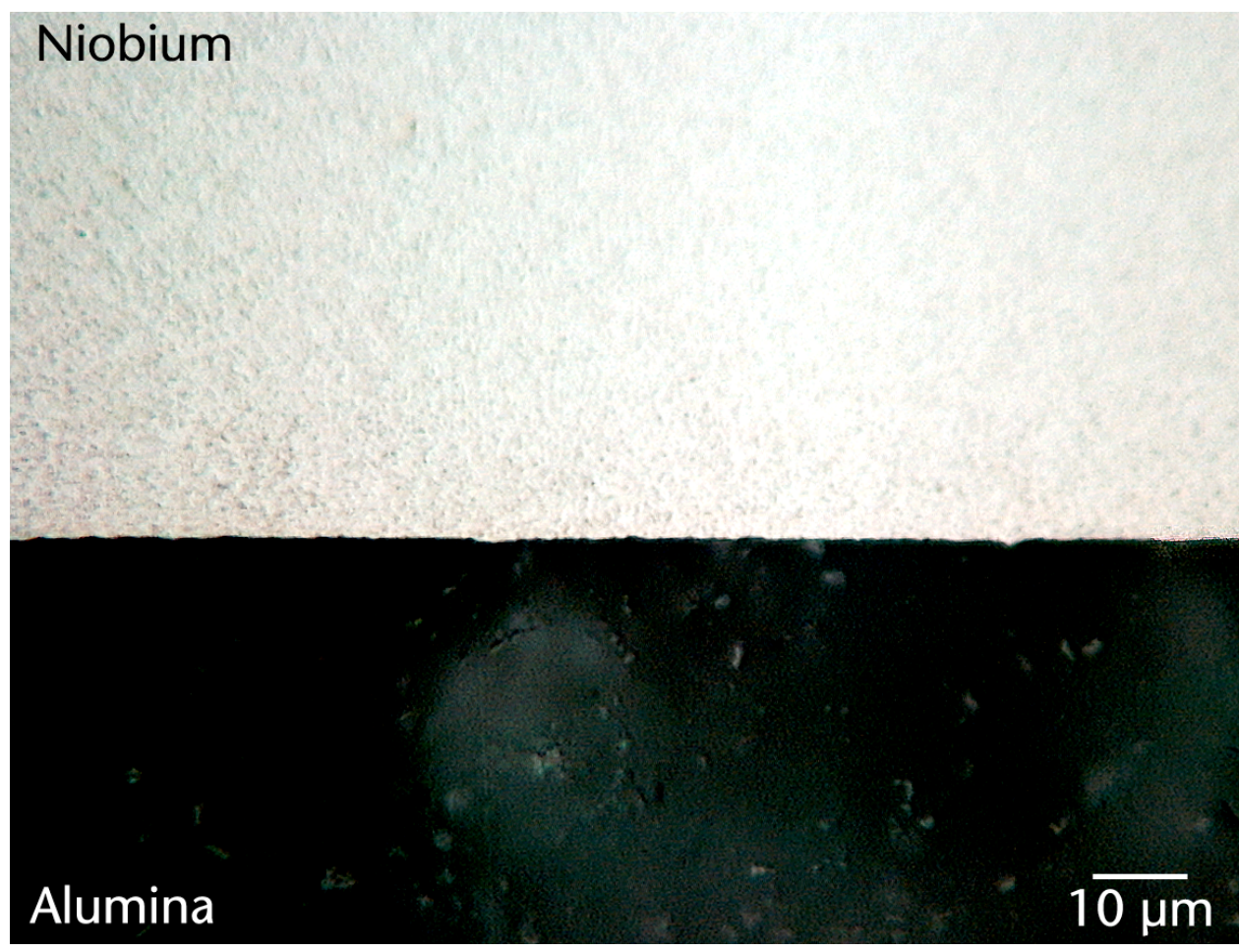

Figure 3: Optical micrograph of a high-purity alumina-niobium interface in cross-section. The interface is free of secondary phases. 


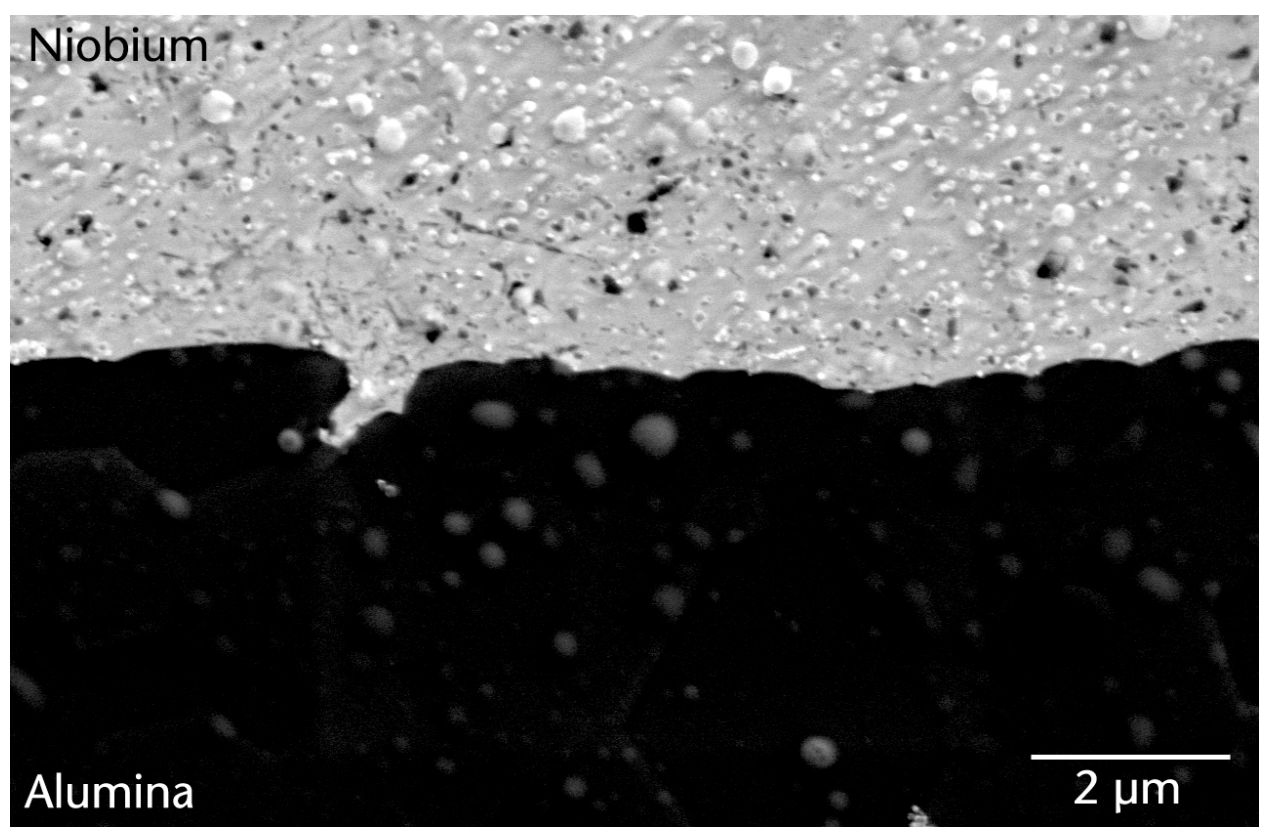

FIgURE 4: SEM image of a high-purity alumina-niobium interface in cross-section. Note the rough interface, due to penetration of the niobium into the alumina grain-boundary grooves and other surface irregularities. 


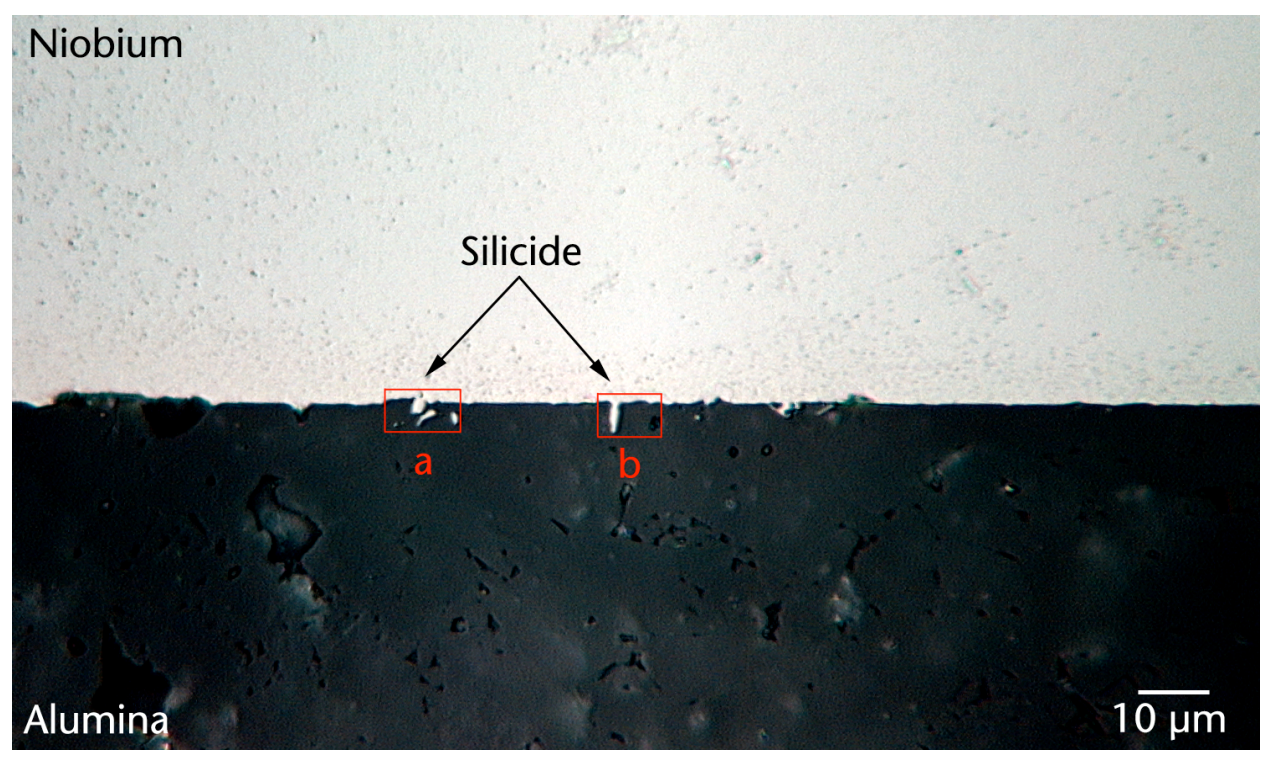

Figure 5: Optical micrograph of a lower-purity alumina-niobium interface in cross-section. Silicide precipitates are evident at the interface. The boxes labeled "a" and " $b$ " are the regions shown in the SEM images of FIgUREs 6 and 7, respectively. 


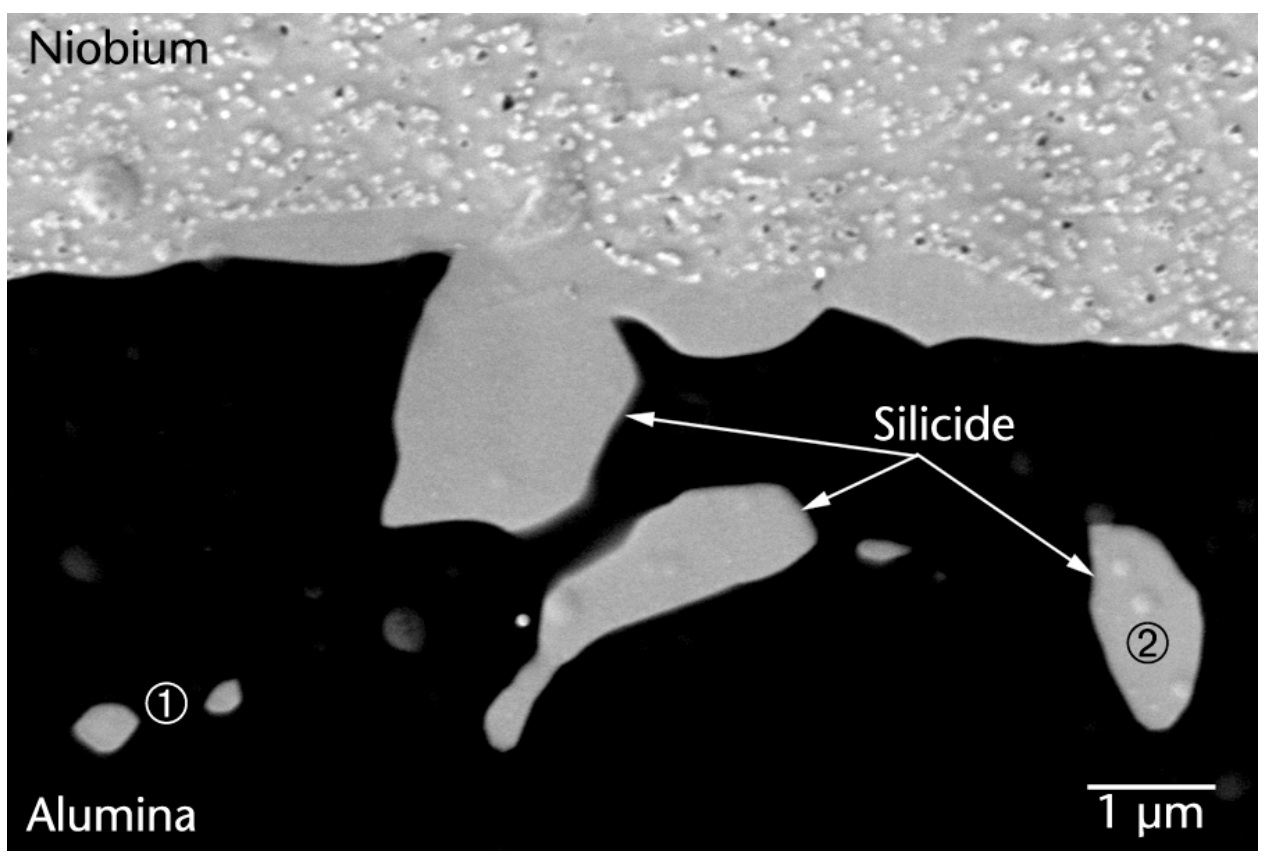

FIGURE 6: SEM image of niobium silicide precipitates at the alumina-niobium interface and slightly away from the interface at alumina grain boundaries. 


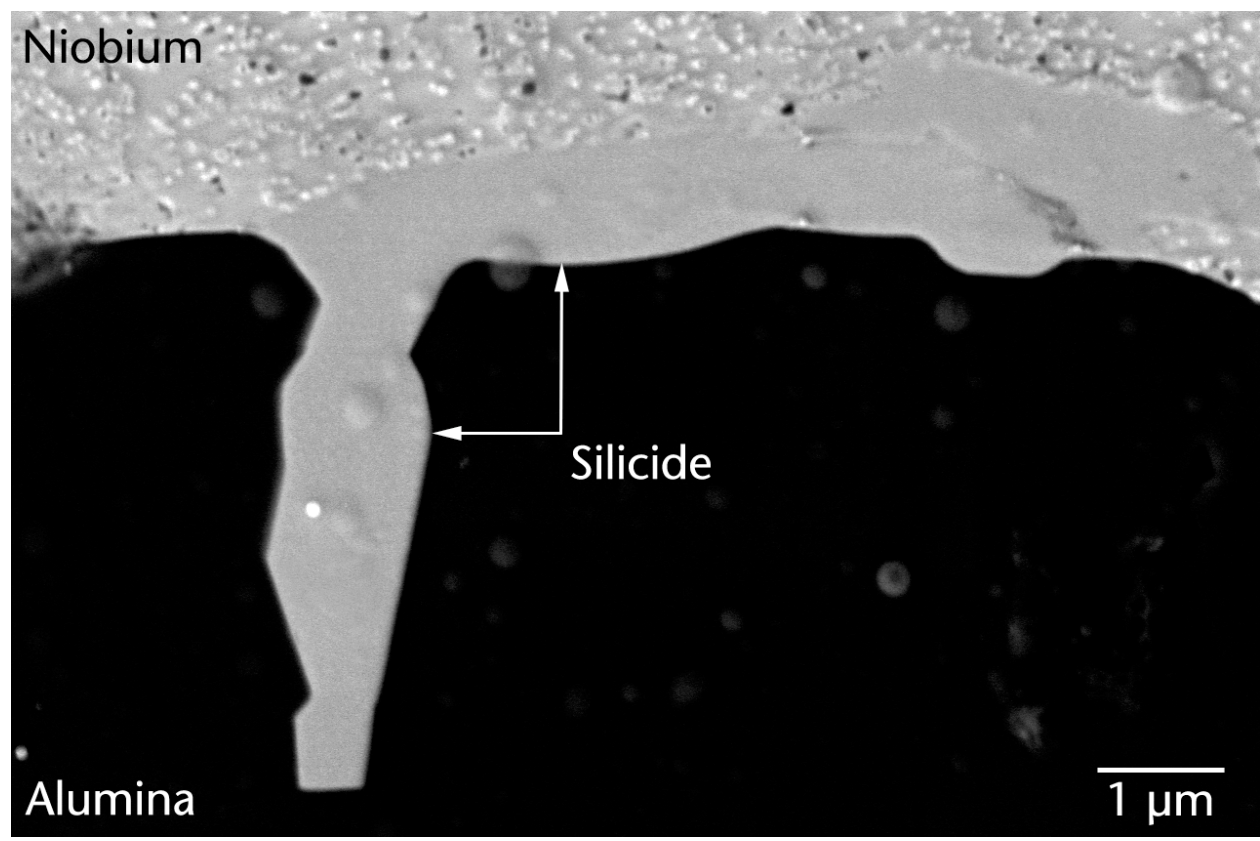

FIGURE 7: SEM image of a niobium silicide precipitate at the alumina-niobium interface and extending away from the interface along an alumina grain boundary. 


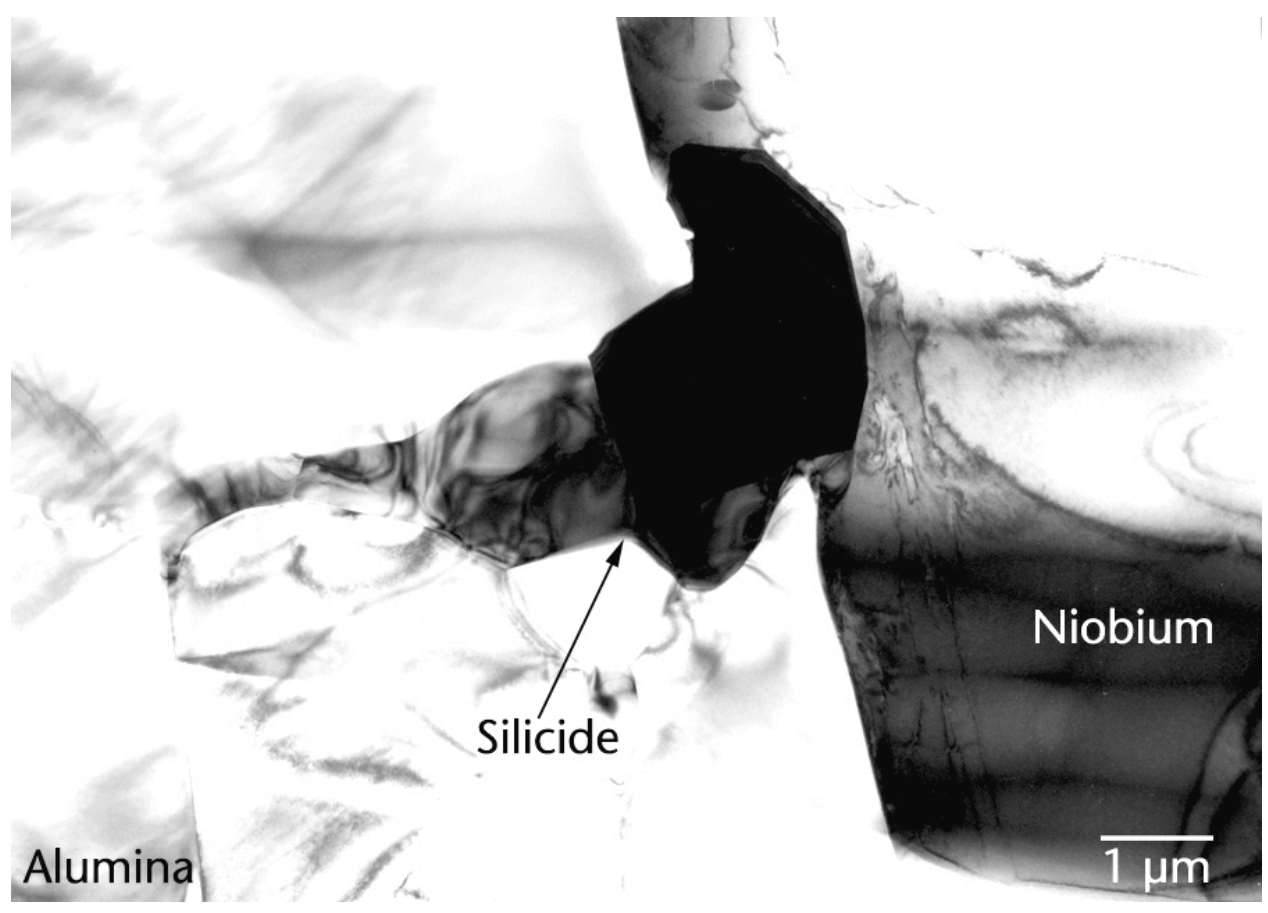

FIgure 8: Bright-field TEM image of a niobium silicide precipitate extending from the aluminaniobium interface into the alumina along a grain boundary. 


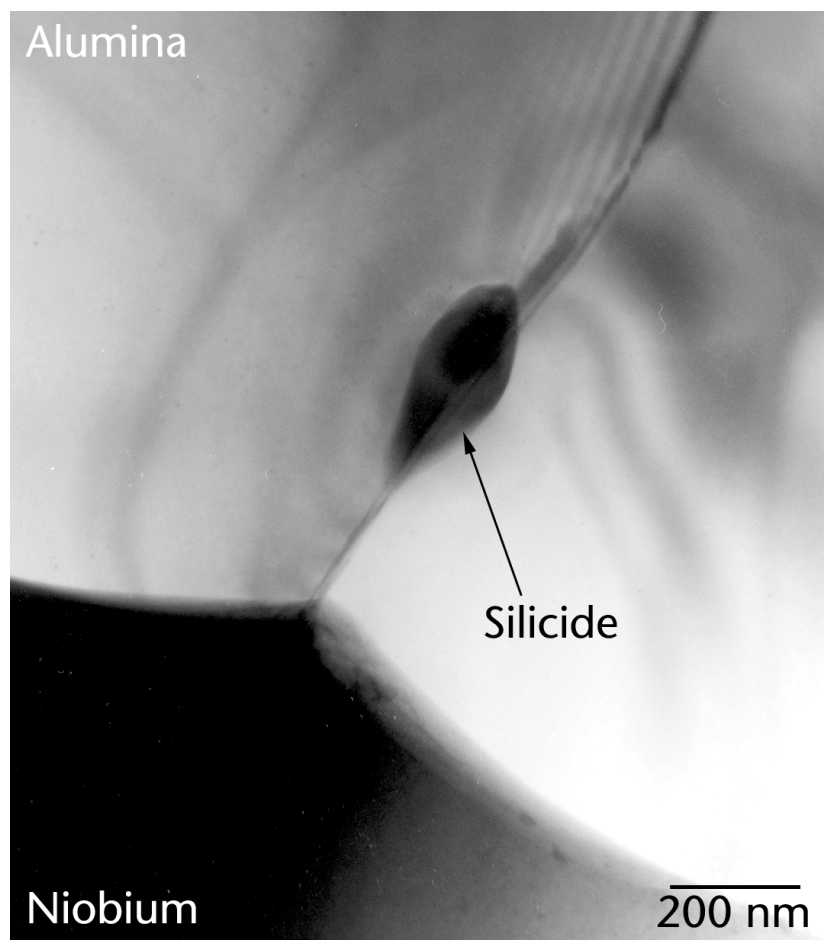

Figure 9: Bright-field TEM image of a niobium silicide precipitate away from the aluminaniobium interface at an alumina grain boundary. 


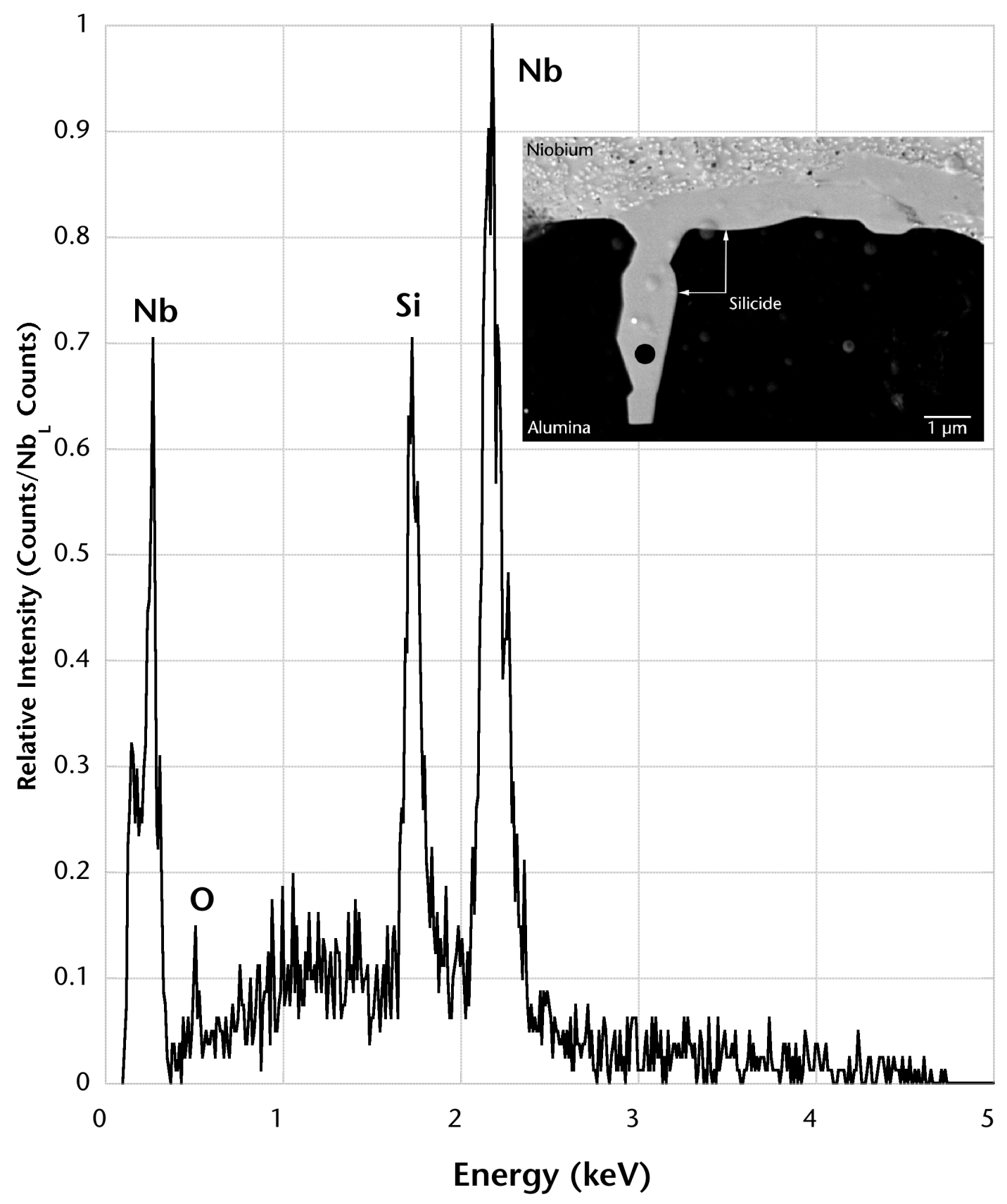

Figure IO: EDS spectrum obtained in the SEM from the region indicated. The precipitate is a niobium silicide. 


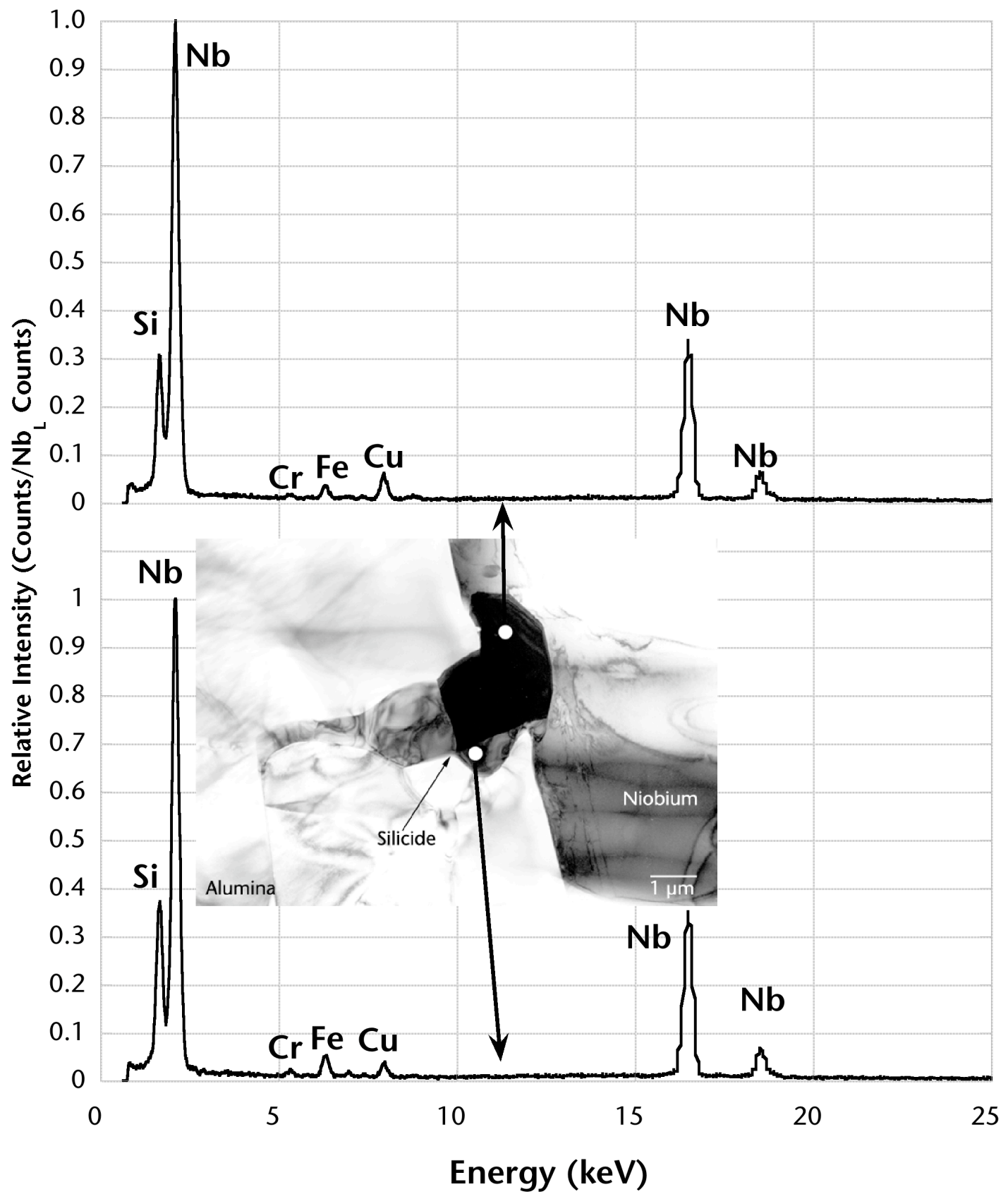

FIGURE II: EDS spectra obtained in the TEM from the regions indicated. The composition of the precipitate in the grain at the alumina-niobium interface (top spectrum) is consistent with the $\mathrm{Nb}_{5} \mathrm{Si}_{3}$ phase. The $\mathrm{Nb}: \mathrm{Si}$ ratio is lower away from the interface (bottom spectrum). 